\title{
Substance abuse among students in selected secondary schools of an urban community of Oyo-state, South West Nigeria: implication for policy action
}

\author{
Ajibola Idowu ${ }^{1}$, Ayodele Olatayo Aremu ${ }^{1}$, Aderonke Olumide ${ }^{1}$, Ayotunde Olumuyiwa Ogunlaja $^{2}$
}

1. Department of Community Medicine, Bowen University Teaching Hospital, Ogbomoso, Nigeria.

2. Department of Obstetrics and Gynaecology, Bowen University Teaching Hospital, Ogbomoso, Nigeria.

Emails:

Ajibola Idowu: idajibola@yahoo.com, Ayodele Olatayo Aremu: drcapotee@yahoo.com, Aderonke Olumide: aderomide@yahoo.com, Ogunlaja Olumuyiwa Ayotunde: lajamuyiwa@yahoo.com,

\begin{abstract}
Background: Substance abuse among youths is fast becoming a global Public Health concern.

Objectives: This study assessed the prevalence and factors associated with substance abuse in selected public schools in Ogbomoso, South-West Nigeria.

Methods: Cross-sectional study design and multi-stage sampling method were utilized among 249 study participants who gave informed consent/assent. Data were collected using facilitated, self-administered questionnaire.Descriptive and inferential statistics using the Chi-Square test were carried out at $\mathrm{p}<0.05$.

Results: The mean age of our respondents was $16.3 \pm 2 \mathrm{SD} ; 40.0 \%$ of them had positive attitude to substance abuse while $21.7 \%$ had ever consumed alcoholic drinks. In all, 31(26.3\%) of the respondents satisfied the criteria used in defining substance abuse. Tramadol was the most commonly abused substance apart from alcohol; reported by $39.0 \%$ of the substance abusers. Most (35.5\%) of the substance abusers did so believing it could enhance their academic performance. The proportion of respondents who were substance abusers was significantly higher among students who had not received any formal lectures on the subject at school compared to those who had. $(47.5 \%$ vs $29.7 \% ; \mathrm{p}=0.023)$.

Conclusion: Our findings underscore an urgent need to intensify awareness against substance abuse among secondary school students in Nigeria.

Keywords: Substance Abuse, Youth, Adolescents, attitude, secondary schools, Nigeria.

DOI: https://dx.doi.org/10.4314/ahs.v18i3.36

Cite as: Idown A, Aremu AO, Olumide A, Ogunlaja AO. Substance abuse among students in selected secondary schools of an urban community of Oyo-state, South West Nigeria: implication for policy action. Afri Health Sci. 2018;18(3): 776-785. https:/ /dx.doi.org/10.4314/ahs.v18i3.36
\end{abstract}

\section{Introduction}

According to the World Health Organization (WHO),Substance abuse refers to the harmful or hazardous use

\section{Corresponding author:}

Ajibola Idowu,

Department of Community Medicine,

BowenUniversity Teaching Hospital,

Ogbomoso, Nigeraia.

Tel: +234-8137974759

E-mail: idajibola@yahoo.com of psychoactive substances, including alcohol and illicit drugs ${ }^{1}$. It is now a major Public Health challenge all over the world. Complications of substance abuse by young people are grave including: increased odds of engaging in risky sexual behaviour, personality disorders,sexual violence, criminal tendencies and drug dependence among others.

Globally, the harmful use of alcohol alone has been estimated to result in 3.3 million deaths each year and at least 15.3 million persons worldwide have been documented to be suffering from drug use disorders ${ }^{1}$. In 2008, 155 to 250 million people all over the world were estimated to

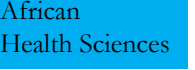

(C) 2018 Idowu et al. Licensee African Health Sciences. This is an Open Access article distributed under the terms of the Creative commons Attribution License (https://creativecommons.org/licenses/BY/4.0), which permits unrestricted use, distribution, and reproduction in any medium, provided the original work is properly cited. 
have used psychoactive substances with cannabis being the most commonly abused substance. WHO estimated that $0.7 \%$ of the global burden of disease in 2004 was due to cocaine and opioid use, with the social cost of illicit substance use being in the region of $2 \%$ of Gross Domestic Product (GDP) in those countries which have measured it ${ }^{2}$.

More than 2.6 million young people aged 10 to 24 die each year in the world. These deaths are mostly due to preventable causes such as substance abuse. In fact, not less than $14 \%$ of adolescent girls and $18 \%$ of boys aged 13-15 years in low- and middle-income countries are reported to have been taking alcoholic drinks ${ }^{2}$. This problem is even more grim in some countries in the Western Pacific region of the WHO as more than $50 \%$ of girls aged 10-19 and more than $80 \%$ of boys aged 10-19 had ever consumed alcohol $^{3}$.

This precarious situation is also prevalent in Nigeria as previous studies had revealed high burden of substance abuse among students. For instance, Ogunsola and Fatusi reported that about two-thirds of in-school adolescents in Osun State Nigeria had used substances in both rural $(65.7 \%)$ and urban areas $(66.0 \%)$ respectively ${ }^{4}$. Also, Lawoyin et al in 2005 , revealed that $69.3 \%$ of secondary school students in Igboora, South-west Nigeria were current users of at least one of the illicit drugs ${ }^{5}$. Alex-Hart in a study among secondary school students in Port Harcourt, Southern Nigeria also revealed that $30.6 \%$ of their respondents had ever taken alcoholic drinks before the survey6 while Yisa et al showed that lifetime use of any substance among students in Ibadan, South West Nigeria was $15.3 \%{ }^{7}$. Eeguranti,et al, in a study among secondary school students in Oshogbo, South West Nigeria also reported $20.3 \%$ as the prevalence of substance abuse among the respondents ${ }^{8}$.

Many factors have been identified to be responsible for drug abuse among young people, these include: experimental curiosity, peer pressure, poor socio-economic condition at homes and the need for extra energy for daily activities among others. Also several theories have been propounded to explain why people abuse drugs. Such theories include; personality theory which says that people with low self esteem and poor impulse control are at higher risk of drug abuse. However, the learning theo- ry says that drug abuse occur as a result of conditioning, social or instrumental learnings?.

While many studies have been conducted in Nigeria on substance abuse, the menace of this social anomaly has remained unabated particularly among the youths. Our objectives were thus to assess the current burden of substance abuse in our study location and to describe factors that may be associated with continuous practice of substance abuse among secondary school students in Ogbomoso.

\section{Methodology \\ Study location}

The study was conducted among students in selected public schools in Ogbomoso North Local Government Area (LGA) of Oyo State, south-west Nigeria. The LGA has ten public secondary schools ${ }^{10}$.

Study design- Cross-sectional study design was employed.

Sample size calculation: The required sample size was calculated using Leslie Kish formula for single proportions. Based on findings from similar studies conducted in Jos, North Central Nigeria ${ }^{11}, 15 \%$ of our respondents were assumed to have engaged in substance abuse. A response rate of $90 \%$ (0.9) was envisaged among the respondents and the margin of error was set at $5 \%$. Thus a minimum sample size of 218 was estimated for the study but 270 questionnaires were administered.

Inclusion criteria: Students in senior classes who gave their assent/consent to participate in the study and whose school authority gave us permission were recruited into the study.

Exclusion criteria: Students with significant physical or mental handicap, which could affect their ability to respond validly to the study instrument, were excluded from the study.

Sampling technique: Multi-stage sampling method was used to select eligible respondents over a period of one month (May, 2017). In the first stage, two co-educational public secondary schools were selected by balloting from the list of ten government secondary schools within the LGA. The selected schools were Ori-Oke and Anglican Grammar Schools, Ogbomoso. The number of respon- 
dents selected per school was proportionate to their population sizes using the formula: Number of students in a school divided by total number of students in the two selected schools, multiplied by 218 .

Stage two involved selection of classes from each levels of SSS1 and SSS2; the two schools visited had more than one class per class-level. Two of such classes were selected by balloting. Stage three involved selecting eligible respondents from the selected classes; a proportionate sample was taken from the selected classes based on their sizes and already determined number of respondents allotted to the school. Respondents from selected classes were selected using systematic sampling technique; the sampling interval was calculated based on the number of students in the class and the number of respondents to be selected from the class. The male to female ratio in each class was also considered during the selection such that a fair proportion of both sexes were selected. The first participant was selected by balloting.

\section{Data collection method and instrument}

Data were collected in May, 2017 using a facilitated self-administered questionnaire developed by reviewing previous studies. Questions were asked on respondents' socio-demographic characteristics, awareness on drug abuse, attitude to and practice of drug abuse. Ten medical students of Bowen University Teaching Hospital were trained on how to administer the questionnaire to youths and adolescents and assisted in data collection. Eligible respondents from selected schools were gathered in halls provided by the respective schools; this was done in order not to disrupt the flow of lectures of the students. The purpose of the study was reiterated as this has been explained in the consent/assent form given to them a day before the survey. Questionnaires were distributed and the trained medical students moved round the hall to facilitate the questionnaire completion process. Spaces were created between the respondents and they were encouraged to give their honest and independent answers to questions.

\section{Pre-testing}

The instrument was pretested among 50 male and female students from a secondary school in Ogbomoso South LGA. The school was a co-educational public school; similar to the schools used for the main study. The exercise helped in assessing appropriateness of the questions in eliciting desired responses. Ambiguous questions were re-phrased or removed in line with study objectives.

\section{Ethical consideration}

Approval for the study was obtained from the Ethical Review Committee of the Bowen University Teaching Hospital, Ogbomoso and permission obtained from authorities of the participating schools. Written assent/consent were also obtained from study participants. Participation was entirely voluntary, confidentiality was ensured; codes rather than participants' names were used as personal identifiers and data were stored in a computer that was only accessible to the principal investigator.

\section{Measures}

Attitude towards substance abuse: Eight statements were positively phrased and used to assess respondents' attitude towards substance abuse; the response to each question was rated using Likart scale ranging from strongly agreed (5 points) to indifferent( 3 points) and strongly disagree, 1 point. Each respondent was rated over 40 points; those who scored less than 20-points were categorized as having negative attitudes to substance abuse (i.e did not approve of substance use for any reason).

Substance abuse: Participants who had ever been involved in harmful alcohol use,cigarette smoking or intake of illicit/illegal drugs such as heroin, cocaine and marijuana were classified as drug abusers. Harmful consumption of locally brewed alcoholic drinks such as local gins and palm wine was also viewed as substance abuse by the authors.

\section{Statistical analysis}

Data were edited on the field daily and entered into Statistical Package for Social Sciences (Version 21.0)12 for analyses. Data were presented using tables and charts. Chi-square test was used to compare categorical variables and level of statistical significance set at $\mathrm{p}<0.05$.

\section{Results}

Two hundred and seventy questionnaires were administered but 249 were returned satisfactorily completed; giving a response rate of $92.0 \%$. As displayed in Table 1, 
the mean age of the respondents was $16.3 \pm 2 \mathrm{SD}$ while the age range was between nine and 28 years. Almost half $(49.4 \%)$ of the respondents were early adolescents, $51.0 \%$ were male students, more than half $(58.2 \%)$ were in SS1 while $87.6 \%$ were Christians. Most (69.1\%) of the respondents live with both parents and have their educations jointly sponsored by them (64.7\%). Almost half $(45.8 \%)$ of the fathers attained secondary education.

Table 1: Respondents' socio-demographic characteristics

\begin{tabular}{|c|c|c|}
\hline Variable & Frequency & Percent \\
\hline \multicolumn{3}{|l|}{ Age } \\
\hline Early adolescent & 14 & 5.6 \\
\hline Middle adolescent & 123 & 49.4 \\
\hline Lateadolescent & 104 & 41.8 \\
\hline$\geq 20$ years & 8 & 3.2 \\
\hline Mean age & $16.3 \pm 2 S D$ & \\
\hline \multicolumn{3}{|l|}{ Sex } \\
\hline Male & 127 & 51.0 \\
\hline Female & 122 & 49.0 \\
\hline \multicolumn{3}{|l|}{ Class Level } \\
\hline SS 1 & 145 & 58.2 \\
\hline SS 2 & 104 & 41.8 \\
\hline \multicolumn{3}{|l|}{ Religion } \\
\hline Christianity & 218 & 87.6 \\
\hline Islam & 28 & 11.2 \\
\hline Traditional & 3 & 1.2 \\
\hline \multicolumn{3}{|l|}{ Living situation } \\
\hline Father only & 14 & 5.6 \\
\hline Mother only & 43 & 17.3 \\
\hline Both parents & 172 & 69.1 \\
\hline Siblings & 9 & 3.6 \\
\hline $\begin{array}{l}\text { Others(staying alone or with } \\
\text { friends) }\end{array}$ & 11 & 4.4 \\
\hline \multicolumn{3}{|l|}{ Father's educational level } \\
\hline No formal education & 15 & 6.0 \\
\hline Primary & 30 & 12.1 \\
\hline Secondary & 90 & 36.1 \\
\hline Tertiary & 114 & 45.8 \\
\hline \multicolumn{3}{|l|}{ Sponsorship } \\
\hline Father only & 38 & 15.3 \\
\hline Mother only & 40 & 16.1 \\
\hline Both parents & 161 & 64.7 \\
\hline Siblings & 5 & 2.0 \\
\hline Self sponsorship & 5 & 2.0 \\
\hline
\end{tabular}


In Table 2, 83.9\% of the students said they had heard of information in $48.0 \%$ of those who were aware of about substance abuse; school teachers were the sources substance abuse (Figure 1).

Table 2: Awareness, attitude towards and practice of respondents on substance abuse

\begin{tabular}{|c|c|c|}
\hline Variable & Frequency & Percent \\
\hline \multicolumn{3}{|c|}{$\begin{array}{l}\text { Ever received lectures on } \\
\text { substance abuse at school }\end{array}$} \\
\hline Yes & 209 & 83.9 \\
\hline No & 40 & 16.1 \\
\hline $\begin{array}{l}\text { Attitude towards subs } \\
\text { abuse }\end{array}$ & & \\
\hline Positive & 99 & 40.0 \\
\hline Negative & 150 & 60.0 \\
\hline \multicolumn{3}{|c|}{ Ever consumed alcoholic drink } \\
\hline Yes & 54 & 21.7 \\
\hline No & 194 & 78.3 \\
\hline \multicolumn{3}{|c|}{$\begin{array}{l}\text { Types of alcoholic drinks } \\
\text { ever consumed }\end{array}$} \\
\hline Beer & 7 & 13.0 \\
\hline Palm wine & 42 & 77.8 \\
\hline Local gin & 5 & 9.3 \\
\hline \multicolumn{3}{|c|}{$\begin{array}{l}\text { Last episode of alcohol } \\
\text { consumption }\end{array}$} \\
\hline One day prior to the survey & 13 & 24.1 \\
\hline Within one week ago & 10 & 18.5 \\
\hline Within one month ago & 31 & 57.4 \\
\hline Overall & & \\
\hline of substanceabuse & 31 & 26.3 \\
\hline Yes & 87 & 73.7 \\
\hline \multicolumn{3}{|c|}{ No } \\
\hline \multicolumn{3}{|c|}{ Types of substance ever abused } \\
\hline \multicolumn{3}{|c|}{ Caffeine } \\
\hline Cigarette smoking & 9 & 29.0 \\
\hline Cocaine & 3 & 10.0 \\
\hline Tramadol & 4 & 12.9 \\
\hline Heroin & 12 & 39.0 \\
\hline \multirow[t]{2}{*}{ Cannabis } & 3 & 10.0 \\
\hline & 0 & 0.00 \\
\hline Last time any & & \\
\hline \multicolumn{3}{|l|}{ the substances was abused } \\
\hline On the day of the survey & 7 & 22.6 \\
\hline One day before the survey & 7 & 22.6 \\
\hline Within the last one week & 8 & 25.8 \\
\hline Within the last one months & 9 & 29.0 \\
\hline \multicolumn{3}{|c|}{$\begin{array}{l}\text { Who introduced you to the } \\
\text { practice of substance abuse }\end{array}$} \\
\hline Parents & 5 & 16.1 \\
\hline Siblings/relatives & 4 & 12.9 \\
\hline Friends & 20 & 64.5 \\
\hline Others & 2 & 6.5 \\
\hline
\end{tabular}




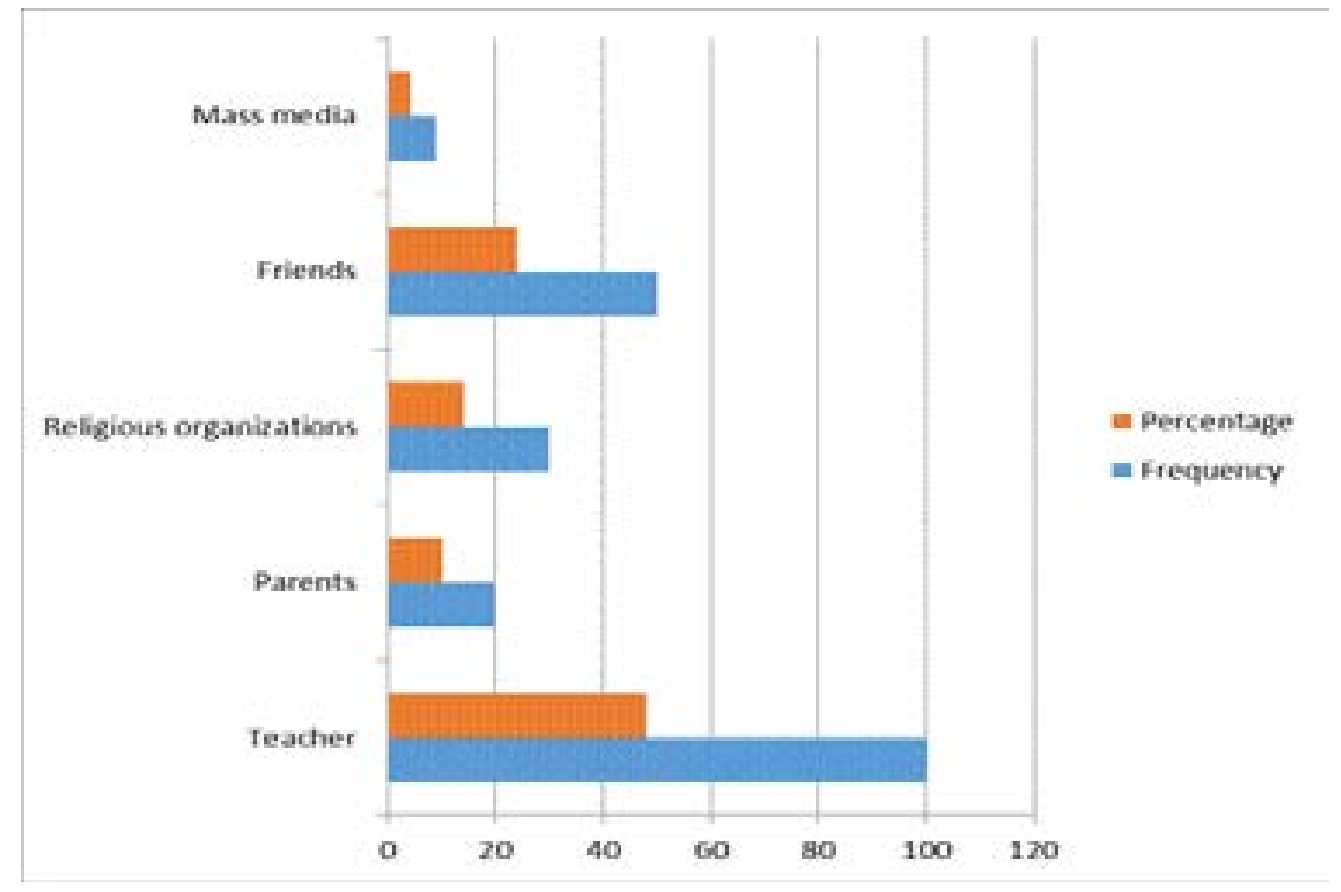

Figure 1: Respondents' sources of information on substance abuse

Forty percent of our respondents approved of substance abuse (had positive attitude to subsistence abuse). Almost a quarter $(21.7 \%)$ had ever consumed alcohol containing drinks, palm wine was the most common alcoholic drink ever consumed; reported by $77.8 \%$ of the respondents who had ever taken alcohol. Close to one quarter $(24.1 \%)$ of those who consumed alcohol said it was taken a day prior to the survey while $57.4 \%$ of them agreed to have taken alcoholic drinks within the past one month before the survey. In all, 31(26.3\%) of the respondents satisfied the criteria used in defining substance abuse in this study, Tramadol was the most commonly abused substance; reported by $39.0 \%$ of the drug abusers. Most (35.5\%) of the drug abusers did so to enhance their intellectual capacities (Figure 2). 


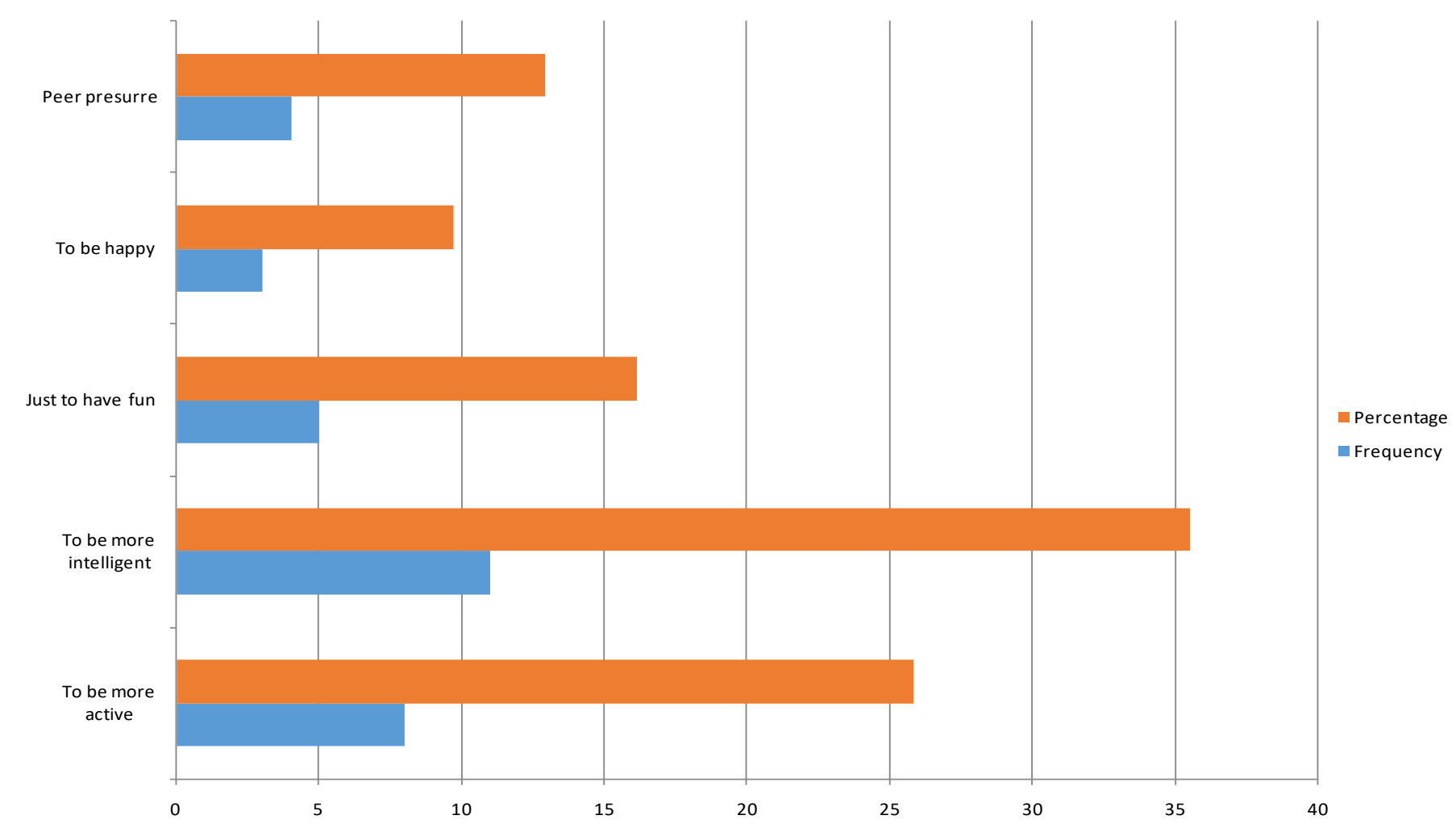

Figure 2: Reasons for substance abuse among respondents

As shown in Table 3, the proportion of respondents who were substance abusers was significantly higher among students who had not received any formal lectures on substance abuse at school compared to those who had been taught (47.5\%vs $29.7 \% ; \mathrm{p}=0.023)$. Other variables were not significantly related to the practice of substance abuse in our study population. 
Table 3: Factors associated with substance abuse among the respondents

\begin{tabular}{|c|c|c|c|c|c|}
\hline \multirow[t]{2}{*}{ Variable } & \multicolumn{2}{|c|}{ Practice of substance abuse } & \multirow[t]{2}{*}{ Total } & \multirow[t]{2}{*}{$x^{2}$} & \multirow[t]{2}{*}{ P-value } \\
\hline & $\begin{array}{l}Y E S \\
N=54 n(\%)\end{array}$ & $\begin{array}{l}\mathrm{NO} \\
\mathrm{N}=195 \\
\mathrm{n}(\%)\end{array}$ & & & \\
\hline Age group & & & & 0.871 & 0.31 \\
\hline Early adolescents & $3(21.4)$ & $11(78.6)$ & 14 & & \\
\hline Mid adolescents & $25(20.3)$ & 98(79.7) & 123 & & \\
\hline Late adolescents & $25(24.0$ & $79(76.0)$ & 104 & & \\
\hline Older students & 1912.5) & $7(87.5)$ & 8 & & \\
\hline Sex & & & & 0.572 & 0.450 \\
\hline Male & $30(23.6)$ & $97(76.4)$ & 127 & & \\
\hline Female & 24(19.7) & $98(80.3)$ & 122 & & \\
\hline Class level & & & & 1.154 & 0.283 \\
\hline SS1 & $28(19.3)$ & $117(80.7)$ & 145 & & \\
\hline SS2 & $26(25.0)$ & $78(75.0)$ & 104 & & \\
\hline Religion & & & & $1.644^{* *}$ & 0.602 \\
\hline Christianity & $47(21.6)$ & $171(78.4)$ & 218 & & \\
\hline Islam & $7(25.0)$ & $21(75.0)$ & 28 & & \\
\hline Traditional & $0(0.0)$ & $3(100.00$ & 3 & & \\
\hline Living situation & & & & $1.741^{* *}$ & 0.823 \\
\hline Fatheronly & $3(21.4)$ & $11(78.6)$ & 14 & & \\
\hline Mother only & $8(18.6)$ & $35(81.4)$ & 43 & & \\
\hline Both parents & $40(23.3)$ & $132(76.7)$ & 172 & & \\
\hline Siblings/relative & $2(22.2)$ & $7(77.8)$ & 9 & & \\
\hline others & $1(9.1)$ & 10(90.9) & 11 & & \\
\hline Mothers education & & & & 2.296 & 0.513 \\
\hline No formal education & $3(25.0)$ & $9(75.0)$ & 12 & & \\
\hline Primary & $9(29.0)$ & $22(71.0)$ & 31 & & \\
\hline Secondary & $24(23.3)$ & 79(76.7) & 103 & & \\
\hline Tertiary & 18(17.5) & $85(82.5)$ & 103 & & \\
\hline Educational sponsorship & & & & $5.485^{* *}$ & 0.241 \\
\hline Father only & $4(10.5)$ & $34(89.5)$ & 38 & & \\
\hline Mother only & $7(17.5)$ & $33(82.5)$ & 40 & & \\
\hline Both parents & $40(24.8)$ & $121(75.2)$ & 161 & & \\
\hline Siblings/relative & $1(20.0)$ & $4(80.0)$ & 5 & & \\
\hline others & $2(40.0)$ & $3(60.0)$ & 5 & & \\
\hline $\begin{array}{l}\text { Ever received lectures on } \\
\text { substance abuse at school }\end{array}$ & & & & 4.87 & $0.023^{*}$ \\
\hline Yes & $62(29.7)$ & $147(70.3)$ & 209 & & \\
\hline No & $19(47.5)$ & $21(52.5)$ & 40 & & \\
\hline Attitude to substance abuse & & & & 0.632 & 0.427 \\
\hline Positive & $24(24.2)$ & $75(75.2)$ & 99 & & \\
\hline Negative & $30(20.0)$ & $120(80.0)$ & 150 & & \\
\hline
\end{tabular}




\section{Discussion}

Almost a quarter (21.7\%) of our respondents had ever consumed alcohol containing drinks. Previous studies have implicated alcohol as one of the most commonly abused substances among Nigerian youths. For example, Igwe et al in 2009 revealed that $31.6 \%$ of secondary school students who were substance abusers in Enugu, Nigeria had consumed alcohol ${ }^{13}$. Alex-Hart also reported a figure of $30.6 \%$ as the proportion of secondary school students in Port Harcourt, Nigeria who had taken alcoholic drinks before the survey ${ }^{6}$. In many Nigerian communities, alcohol consumption is socially acceptable; the youth consumes alcohol as a sign of maturity. Besides, alcoholic drinks are freely served in many occasions in Nigeria while people take pleasure in daily alcohol consumption with friends in various joints and club houses as a means of relaxation. Also, alcohol producing companies are sponsoring football and other sporting events which are largely viewed by the Nigerian youths. Moreover, popular Nigerian actors and actresses are paid to advertise alcoholic drinks. All these could have served as push factors for increased alcohol consumption among the Nigeria youths.

In all, $31(26.3 \%)$ of the respondents satisfied the criteria used in defining substance abuse in this study. The prevalence of substance abuse in our study location was consistent with findings from previous studies. For instance Yisa et $\mathrm{al}^{7}$, revealed that lifetime use of any substance among students in Ibadan was $15.3 \%$ with alcohol being the most commonly abused substance. Eeguranti,et al, in a study among secondary school students in Oshogbo also reported a prevalence of $20.3 \%{ }^{8}$. Onoja in 2016, equally found out that $15.0 \%$ of students in public schools in Jos, Nortth Central Nigeria engaged in substance abuse $^{11}$. Contrariwise, other studies had reported higher figures compared to the finding from the current study. The prevalence of substance abuse as reported by Lawoyin et al, was 69.3\% among secondary school students in a rural community of Oyo State Nigeria ${ }^{5}$. The fact that the study was rural-based could have accounted for the higher figure; rural dwellers tend to have easier access to some local psychoactive substances such as kolanut which constituted the highest proportion of substances abused in the study. Also, Idris and Sambo in 2009, reported that $56 \%$ of in-school adolescents in Zaria, North Western Nigeria had used at least one pyscho-active sub- stances before the survey ${ }^{14}$. Fathers of $45.8 \%$ of our respondents attained tertiary education. This could have exposed them to appropriate information on dangers associated with substance abuse thus making them to serve as positive role models for their wards against substance abuse. Also, $64.7 \%$ of our respondents had their education jointly sponsored by their parents. Family connectedness as revealed by Ogunsola and Fatusi in 2015, has been reported as a strong protective factor against substance abuse $e^{4}$.

Apart from alcohol abuse, tramadol was the most commonly abused substance in the current study. This is in contrast to findings from some previous studies which had implicated cannabis as the most abused illicit drugs ${ }^{2}$. Tramodol abuse is an emerging menace in Nigeria. This potent pain killer is abused for its euphoric actions by the youths thus leading to dependency and other associated social consequences.

Most (35.5\%) of the drug abusers in the current study erroneously did so with the view to enhance their intellectual/ academic performances. This is in contrast to findings from the Kaduna ${ }^{14}$ study which revealed experimentation as the the commonest push factor for use of psycho-active substances. Psycho-active substances tend to increase alertness, but mental concentration tend to be impaired in most instances. Also, positive correlation between substance abuse and good academic performance is yet to be documented in the medical literature.

\section{Conclusion}

The burden of substance abuse is still high in our study population and the prevalence was significantly higher among students who had not received any formal teachings on the subject. It therefore becomes imperative to incorporate teachings on substance abuse into the national school curriculum for secondary school students. The National School Health Policy needs to be expanded to incorporate this vital issue. The law enforcement agents regulating drug trafficking in and out of Nigeria should begin to beam their search lights on secondary school students. Regular checks of students' bags and belongings should routinely be carried out by school teachers. Awareness campaigns on dangers associated with substance abuse should be intensified in various secondary schools in Nigeria. Social media and other channels of communication could be positively engaged in reaching 
the youths on this subject. Meanwhile, advertisement of alcoholic drinks using celebrities who are often seen as role models to the younger ones should be discouraged. Lastly, prescription and availability of certain drugs such as Tramadol should be strictly monitored and regulated in Nigeria.

\section{Study limitation}

The study focused on eliciting responses on a very sensitive matter-substance abuse, the practice of which is viewed as socially unacceptable in most Nigerian societies. Thus the fear that students might be punished by their teachers if discovered to have been engaging in such practices might have biased this study. The fact that the questionnaires were anonymous could have however reduced this bias. Due to financial constraints, we could not take samples from study participants for laboratory/ chemical analysis to ascertain their true status with regards to substance abuse. Participating students were however encouraged to give honest answers to questions asked to increase the validity of the study.

\section{Acknowledgement}

Authors wish to appreciate the authorities of Anglican and Ori-Oke Grammar schools for granting us permission for this study to be conducted in their schools. We also acknowledge the efforts of the part four medical students of Bowen University Teaching Hospital, Ogbomoso, for assisting in data collection.

\section{Conflict of interest}

Authors declared no conflict of interest in the conduct of this study.

\section{References}

1. World Health Organization. Substance Abuse.2014. Available on http://www.who.int/topics/substance_ abuse/en/. Accessed October $12^{\text {th }}, 2017$

2. World Health Organization. Management of substance use. 2012. Available on http://www.who.int/ substance_abuse/facts/psychoactives/en/. Retrieved on October $12^{\text {th }}, 2017$.

3. World Health Organization Western Pacific Region; Fact sheet on adolescent health 2012. Available on:http://www.wpro.who.int/mediacentre/factsheets/ docs/fs_201202_adolescent_health/en/. Accessed on $12^{\text {th }}$ October,2017
4. Ogunsola O.O. and Fatusi A.O.Risk and protective factors for adolescent substance use: a comparative study of secondary school students in rural and urban areas of Osun State, Nigeria. International Journal of $A d$ olescent Medicine and Health. 2016;29(3). DOI: https://doi. org/10.1515/ijamh-2015-0096

5. Lawoyin T.O.,Ajumobi O.O.,Abdul M.M., Abdul Malik J.O., Adegoke D.A., Adebiyi O.A. .Drug use among senior secondary school students in rural Nigeria. Afr J Med Sci. 2005;34(4):355-9. PubMed

6. Alex-Hart B.A., Opara P.I.,Okagua J. Prevalence of alcohol consumption among secondary school students in Port Harcourt, southern Nigeria. Niger I Paed. 2015;42(1):39-45. PubMed

7. Yisa I.O.,Lawoyin T.O.,Fatiregun A.A., Emelumadu O.F. Pattern of substance use among senior students of command secondary schools in Ibadan,Nigeria. Niger J Med. 2009;18(1):98-102. PubMed

8. Eeguranti B.A., Fatoye F.O., Morakinyo O. Stimulant use among secondary school students in Osogbo, Nigeria. The Nigerian Postgraduate Medical Journal. 2009;16(3):218-23. 9. National Institute on Drug Abuse. Theories of drug abuse;selected contemporary perspectives. NIDA Research Monograph 30. March 1980.

10. Oyo state TESCOM. Oyo state post-primary school teaching service commission. Available on http://oyotescom.org/oyotescom/schools.php. Accessed 12 ${ }^{\text {th }}$ October, 2017.

11. Onoja M.O. Prevalence of substance abuse among secondary school students; a comparative study of government and private secondary schools in Jos, Nigeria. National Institute on Drug abuse. 2010. Available on;https:/ / www.drugabuse.gov.gov/international/abstract/prevalence-substance-abuse-among-secondary-school.

12. IBM SPSS Statistics for windows, version 21.0.Armonk,NY:IBM Corp.

13. Igwe W.C., Ojinnaka N., Ejiofor S.O.,Emechebe G.O., Ibe B.C.Socio-demographic correlates of psychoactive substance abuse among secondary school students in Enugu, Nigeria. Europian Journal of Social Sciences. 2009; 12(2):277-83.

14. Idris S.H.and Sambo M.N.(2009). Psycho-active substance use among in-school adolescents in Zaria, north western Nigeria: what are the triggers. Niger J Med. 2009;18(3):291-4.

African Health Sciences Vol 18 Issue 3, September, 2018 